\title{
Self-care after hospital discharge: knowledge is not enough
}

\section{Leora I Horwitz 1,2,3}

In this issue of BMJ Quality and Safety, Greysen and colleagues present results of a large, multi-institutional interview study of readmitted patients' perspectives of post-discharge care. ${ }^{1}$ Investigators interviewed over 1000 patients while they were readmitted to one of 12 academic medical centres and asked them a variety of questions about barriers to recovery after their previous discharge. More than half of patients reported difficulty carrying out the care plan given to them when they were first discharged from the hospital, even though the vast majority reported no difficulties understanding what they were supposed to do.

Post-discharge self-management can be conceptualised as a three-legged stool comprised of knowledge, planning and ability. The patient needs to know what to do (for instance, take a medication three times a day). The patient also needs to have a plan for how to do it (for instance, use a pill box with three slots per day; fill it accurately on a weekly basis; use a reminder system to signal time for medication). And crucially, the patient has to be able and willing to carry out that plan (for instance, buy the medication and pill box; have some help if needed filling it; be awake at the times needed to take the medication). If any of these key components is removed, the stool falls over.

Transitional care has historically focused on the knowledge leg, with notably imperfect results. ${ }^{2}$ In fact, all the widely used process metrics for transitions in care focus on knowledge. The Center for Medicare \& Medicaid Services discharge instruction metric (no longer publicly reported) assessed the accuracy and completeness of information given to patients with heart failure. The three-item Care Transition Measure-3 is comprised of two questions about patients' perceived knowledge and one about whether preferences were taken into account. ${ }^{4}$ The
Hospital Consumer Assessment of Healthcare Providers and Systems postdischarge survey asks whether patients were given information about what to do during their recovery and about whether they understood these instructions. ${ }^{5}$ But as Greysen and colleagues illustrate, discharge planning has much less often focused either on codeveloping plans for success with patients or on identifying patients' ability to carry out those strategies. In this study, only $37 \%$ of patients reported that someone in the hospital had asked prior to discharge if they expected to have difficulty carrying out the postdischarge plan, even though over half did in practice experience such difficulties.

It is important to note that this study is not fully representative of hospitalised patients, nor does it demonstrate an association of post-discharge care challenges with readmission. Cognitively impaired and non-English speaking patients were omitted, despite forming a substantial and high-risk cohort of patients at most hospitals. These patients may have even higher rates of post-discharge challenges. Moreover, the investigators interviewed only readmitted patients; we do not know how often non-readmitted patients have difficulty in adhering to the discharge plan. We therefore cannot be certain that these challenges are associated with readmission, or that improving patients' ability to carry out a post-discharge plan will necessarily improve their outcomes.

Remarkably few studies have asked readmitted patients about their postdischarge experience, but most of those have reported similar results as Greysen et al. ${ }^{6-10}$ Although the insights patients have provided in this and other studies are not particularly novel or surprising to anyone who has tried to follow doctors' instructions, they are useful to remember for those considering readmission reduction programmes. It is by now quite well established that-to the extent anything 
works-multimodal and community-based interventions are the most likely to be effective in reducing readmissions. ${ }^{11} 12$ By contrast, purely educational and telemonitoring-based interventions have been less effective. ${ }^{11}$ This study and others involving patients shed some insight into why a focus on the knowledge leg of the stool is insufficient. We can increasingly be certain that simply ensuring patients' understanding is not sufficient to ensure they adhere to our best laid plans.

The vexing question facing most healthcare systems now, however, is who has-and who should haveresponsibility for shoring up all the legs of the stool. Greysen et al suggest that many of the difficulties encountered by patients would not have been apparent at discharge and arose only when the patient was at home. In addition, some strategies for achieving post-discharge goals may be best arranged in the outpatient setting. Certainly many commentators have noted that community resources and activities are central to effective post-discharge care and have suggested that hospitals should not bear the brunt of the responsibility under federal policies for avoiding readmissions and for helping patients with postdischarge care.

These concerns are reasonable. Readmissions are likely more reflective of community-wide healthcare quality, capacity and access than of hospital care alone. It is also true, however, that hospitals are the 800 pound gorillas in the healthcare environment, with outsized influence on the existence and funding of community resources. Already, hospitals are beginning to change outpatient capacity by creating respite programmes for homeless patients, ${ }^{13}$ staffing skilled nursing facilities, ${ }^{14}$ directly offering outpatient-based transitional care ${ }^{15}$ and a host of other interventions. ${ }^{16}$ Yet, it is clear from this study by Greysen et al and from other studies that, even after much attention to readmissions, hospitals are not yet optimising their own contribution to transitional care.

Ideally, discharging clinicians will learn from these reports of patient experiences to better assess patients' knowledge, capacity and willingness to engage in post-discharge care while working with outpatient clinicians and community agencies to help patients manage and coordinate their care post-discharge. Ideally also, though, community capacity to assist patients in this vulnerable period will improveperhaps with the help of pressure or funding from hospitals. To achieve the best outcomes for our patients, we will need to move beyond simply providing patients with instructions and some useful phone numbers and hoping for the best.
Twitter Follow Leora Horwitz at @leorahorwitzmd

Competing interests None declared.

Provenance and peer review Commissioned; internally peer reviewed.

\section{REFERENCES}

1 Greysen SR, Harrison JD, Kripalani S, et al. Understanding patient-centred readmission factors: a multi-site, mixed-methods study. BMJ Qual Saf 2017;26:32-40.

2 Horwitz LI, Moriarty JP, Chen C, et al. Quality of discharge practices and patient understanding at an academic medical center. JAMA Intern Med 2013;173:1715-22.

3 Makaryus AN, Friedman EA. Patients' understanding of their treatment plans and diagnosis at discharge. Mayo Clin Proc 2005;80:991-4.

4 Coleman EA, Smith JD, Frank JC, et al. Development and testing of a measure designed to assess the quality of care transitions. Int J Integr Care 2002;2: 02 .

5 Giordano LA, Elliott MN, Goldstein E, et al. Development, implementation, and public reporting of the HCAHPS survey. Med Care Res Rev 2010;67:27-37.

6 Long T, Genao I, Horwitz LI. Reasons for readmission in an underserved high-risk population: a qualitative analysis of a series of inpatient interviews. BMJ Open 2013;3:e003212.

7 Kangovi S, Barg FK, Carter T, et al. Challenges faced by patients with low socioeconomic status during the post-hospital transition. J Gen Intern Med 2014;29:283-9.

8 Kangovi S, Grande D, Meehan P, et al. Perceptions of readmitted patients on the transition from hospital to home. J Hosp Med 2012;7:709-12.

9 Cawthon C, Walia S, Osborn CY, et al. Improving care transitions: the patient perspective. J Health Commun 2012;17 (Suppl 3):312-24.

10 Jeffs L, Dhalla I, Cardoso R, et al. The perspectives of patients, family members and healthcare professionals on readmissions: preventable or inevitable? J Interprof Care 2014;28:507-12.

11 Feltner C, Jones CD, Cené CW, et al. Transitional care interventions to prevent readmissions for persons with heart failure: a systematic review and meta-analysis. Ann Intern Med 2014;160:774-84.

12 Jovicic A, Holroyd-Leduc JM, Straus SE. Effects of self-management intervention on health outcomes of patients with heart failure: a systematic review of randomized controlled trials. BMC Cardiovasc Disord 2006;6:43.

13 Johnson SR. Shelter for convalescence. Mod Healthc 2014;44:33-4, 36, 38.

14 Zigmond J. 'SNFists' at work: nursing home docs patterned after hospitalists. Mod Healthc 2012;42:32-3.

15 Meltzer DO, Ruhnke GW. Redesigning care for patients at increased hospitalization risk: the Comprehensive Care Physician model. Health Aff (Millwood) 2014;33: 770-7.

16 Silow-Carroll S, Edwards JN, Lashbrook A. Reducing hospital readmissions: lessons from top-performing hospitals. 2011. http:/www.commonwealthfund.org/ /media/Files/Publications/ Case\%20Study/2011/Apr/1473_SilowCarroll_readmissions_ synthesis_web_version.pdf (accessed 7 Feb 2016). 